\section{Group news}

The following are all based on recent Press Releases.

\section{LIRG LAUNCHES PROGRAMME OF RESEARCH COURSES}

The Library \& Information Research Group (LIRG) are launching a new programme of courses which will enable LIS professionals to develop the skills that they need to understand research and carry it out. Each stage of doing research will be covered in a workshop:

- Managing your research project

- Designing a good questionnaire survey

- Doing research with people: interview and observation

- Creative data analysis

- Getting research results disseminated and used

The programme of courses, Making Research Work For You, is aimed at funded researchers, practitioners who undertake research, and other LIS professionals who will benefit from good research techniques in their work. The course will be a useful refresher for those who studied research methods in their degree course but have not been research active since.

The course will consist of five workshops which will be delivered fortnightly with the first course being offered in London from January 1999 and the second course being offered in York from April. Participants will be able to choose to attend the whole course or they can select particular workshops that interest them. A unique feature of the programme will be that the Library $\&$ Information Research Group will ensure that participants will be supported and mentored by experienced researchers from amongst LIRG's membership.

Philip Payne, Chair of the Library and Information Research Group said:

"We see this as one of the most exciting and significant initiatives ever taken by the Group.
We believe that the programme will help to bridge the gap between research and practice and increase the pool of LIS professionals with the skills that they need to undertake high quality research."

The courses are being supported by the British Library Research \& Innovation Centre. They are being designed and delivered for the Library \& Information Research Group by David Haynes of David Haynes Associates and David Streatfield of Information Management Associates.

Further details:

Jo Glover, LIRG Administrative Officer

Leeds Metropolitan University

Calverley Street, Leeds LS1 $3 \mathrm{HE}$

Tel: 01132835993

Fax: 01132833123

Email: J.Glover@LMU.AC.UK

\section{LIRG CONSULTED ON DCMS COMPREHENSIVE SPENDING REVIEW}

From: Payne, Philip

To: DCMS

Friday, October 2, 1998

I am writing on behalf of the Library and Information Research Group - an independent professional group formed in 1977 to bring together all those interested in library and information research and its application.

The group notes the publication of the DCMS Spending Review and welcomes the opportunity to comment. The group supports the transfer of funding for library and information research from the British Library to the Library and Information Commission. The Group feels that the BL Research and Innovation Centre (BLRIC) undertakes a useful and effective role in distributing research grants. However, we believe that a transfer of this role to the LIC represents a more sensible arrangement in the context of the need to implement the Library and Information Commission's recently published strategy for research, development, and innovation. We also feel that it is unhelpful that British Library Research and Innovation Centre's budget is set within the context of the overall 
British Library budget. The amount available for funding library and information research has consequently not been based upon need but upon budgetary pressures within the British Library. The Group notes the medium term proposal to merge the Library and Information Commission with the Museums and Galleries Commission to create a new powerful Museums and Libraries Council. We believe that this would afford some interesting research opportunities across the current boundaries of libraries and museums. We believe that $£ 1.6 \mathrm{~m}$ p.a. is not adequate to support the research and development required at a time of considerable technological and cultural change for libraries. Consequently, our major concern is that the transfer of the budget for library and information research to LIC and the possible creation of the Museums and Libraries Council do not lead to an erosion in the level of funding for library and information research.

Philip Payne, Chair

Library \& Information Research Group

\section{Dear Mr Payne,}

Thank you for your response to the DCMS consultation. The Secretary of State will be carefully considering all responses when making his conclusions. which will be published later in the year. All respondents will receive a copy.

Annabel Jones, Strategy Unit

Department of Culture, Media, and Sport

\section{STUDY OF ABSTRACTING WINS LIRG POSTGRADUATE PRIZE}

Amanda Tinker from Loughborough University has won the 1998 LIRG Postgraduate Prize for her dissertation, Automatic abstracting: a review and an empirical evaluation. Amanda's study looked at the adequacy and effectiveness of human-produced and machine-produced abstracts. The study stood out for its innovative methodology and the careful and considered way in which it was conducted. A report of Amanda's work will appear in the next issue of Library \&
Information Research News and the prize will be awarded at the Groups' AGM on the 17th. March 1999.

The quality of the nominations received was excellent and Amanda won against intense competition from other entries. The judging panel decided that five dissertations should be highly commended:

Pete Abel (Manchester Metropolitan University) Information on the Military, Security, Police (MSP) trade: an evaluation of commercial and public domain information sources.

Peter Dalton (University of Central England) Information audit: a critical analysis of audit procedures and some considerations of its place in information service chains.

Thea Farley (University of Wales, Department of Information \& Library Studies) People and change: the management of change in academic libraries in the 1990s.

Jane Jones (Leeds Metropolitan University) Promoting sleep: information on sleep and sleep disorders for general practitioners.

Tracey Mellor (University of Northumbria) Examination of the information needs of small and medium sized enterprises amd information provision in Tyneside.

Those who were highly commended will receive a certificate and a year's free membership of LIRG.

\section{DISASTER STUDYWINS UNDERGRADUATE PRIZE}

Jaspal Kaur of the University of Central England has won the LIRG Undergraduate Prize for 1997. Her investigation into information disaster recovery in a UK law firm won against stiff competition from other Department of Library and Information Studies' nominations. Jaspal carried out her study whilst on placement at Richards Butler Library \& Information Services 
during her BA (Hons) Information \& Library Studies. The adjudicating judge praised the study for being beautifully clear and using a good mix of survey methodology. A report of her work will appear in the next issue of Library \& Information Research News a nd the prize will be awarded at the Groups' AGM on the 17th. March 1999.

\section{DETAILS OF LIRG STUDENT PRIZES}

The Library \& Information Research Group (LIRG) established its student prizes in 1993 to recognise the contribution of student projects to library and information research and to encourage wider dissemination of the findings of exceptional theses and dissertations. One prize of $£ 250$ is awarded each year for an undergraduate student project and one for a postgraduate student project. Schools/Departments of Library and Information Studies nominate their best projects in each category and a judging panel made up of representatives of the Library \& Information Research Group evaluate the entries and choose the winners. The closing date for nominations for the LIRG Undergraduate Prize is 31 st. October 1998, and for the LIRG Postgraduate Prize is 28th. February 1999.

\section{General Procedures and Conditions}

1. Prizes will be awarded to students completing courses leading to a first professional qualification recognised by the Library Association or the Institute of Information Scientists in Schools/Departments of Library and Information Studies.

2. One prize of $£ 250$ will be awarded for (i) an undergraduate student project and (ii) a first professional postgraduate student project.

3. The work of one undergraduate student and one postgraduate student may be submitted by each of the Schools/Departments of Library and Information Studies with a short (no more than 300 words) supporting recommendation.

4. The closing dates for submission are normally the end October for the undergraduate category and the end of February for the postgraduate category. Work completed at any time during the twelve months up to the relevant closing date is eligible.

5. Projects to be submitted shall be those completed as part of normal course requirements in a course leading to a first professional qualification and shall be of the level which may be called "dissertation", "major project", etc.

6. Research is to be interpreted broadly but must include some original work.

7. A Panel will be appointed by the Library and Information Research Group to judge entries and award prizes. The Panel's decision will be final.

8. The Library and Information Research Group will from time to time publish a set of criteria for the judging of entries.

9. Prize winners shall agree to write a short report for Library and Information Research News

10. LIRG may wish to negotiate publication rights with the prize winner's department or school. Alternatively, LIRG will advise prize winners on the publication of suitable work.

11. One copy of the student's work, and any supporting statement from the

School/Department, should be sent by the appropriate closing date to the Chair of LIRG, Philip Payne, Library Services Manager, Leeds Metropolitan University, Calverley Street, Leeds LS13HE, Email: P.Payne@LMU.AC.UK (telephone 0113283 5966, fax 0113283 3123).

12. The work will be returned to the School/Department after judging. Please contact the Chair of LIRG at the above address if you wish to discuss any aspect of these Prizes.

\section{PRIZE FOR RESEARCH BY PRACTITIONERS}

Have you recently undertaken an investigation or carried out some research for your library or information service? Has someone within your 
organisation carried out some particularly useful study. The work may have fed into decision or policy making. It may mean that operations are carried out more efficiently - or the service is more effective. It may have changed the way in which colleagues see things or contributed to a change in the culture in some significant way.

The Library \& Information Research Group (LIRG) invites entries for the Daphne Clark Prize which is awarded for excellence in practitioner based library and information research. The Prize is for research by practitioners which has made a useful and timely contribution.

The Prize is worth $£ 250$ and entries will be judged each year by a panel made up of members of the Library and Information Research Group. The judging panel will look for evidence of successful innovation based upon sound and transferable research methods. The Prize is intended to encourage the use of sound methodologies in practitioner based library and information research and to encourage wider dissemination of small studies conducted by practitioners.

Entries are acceptable from any individuals or staff teams who have conducted practitioner based research. Their employer can also nominate candidates. Entries should consist of a short summary (2000-5000 words) of the research activity, method, and outcomes. This could be the report of the study supplemented by a brief ${ }^{\circ}$ description of how the research was used. Any sort of research project can be nominated but externally funded projects are not eligible. The research must have been completed within the last two years. Applications should include the name of the candidate(s), a contact address, and a brief $\mathrm{CV}$. Candidates may be required to provide further evidence of the work undertaken (eg working papers, reports, committee papers etc) if required.

Prize winners will be asked to submit a short report describing their research within three months of receiving the Prize. This will be published in the Group's journal, Library \& Information Research News or publicised as considered appropriate by the judging panel. If the research findings have been previously published, then the report submitted for Library and Information Research News must demonstrate some original aspects.

The closing date for applications is 31 st. January 1999 and it is expected that the prize winner will be announced at the Group's AGM in March. Applications should be sent to Philip Payne, Chair, Library \& Information Research Group, Leeds Metropolitan University, Learning Support Services, Calverley Street, Leeds LS1 3HE (telephone 0113283 5966, fax 0113283 3123, email P.Payne@LMU.AC.UK)

In addition ot the prizes described above there is also the Elsevier Science/LIRG Research Awardtypically $£ 1,000$ towards a research project. See pages 7, 14 and 40 of out last number (No. 71) for details and examples.

\section{PRIZEWINNER PRESENTATION IN PARIS}

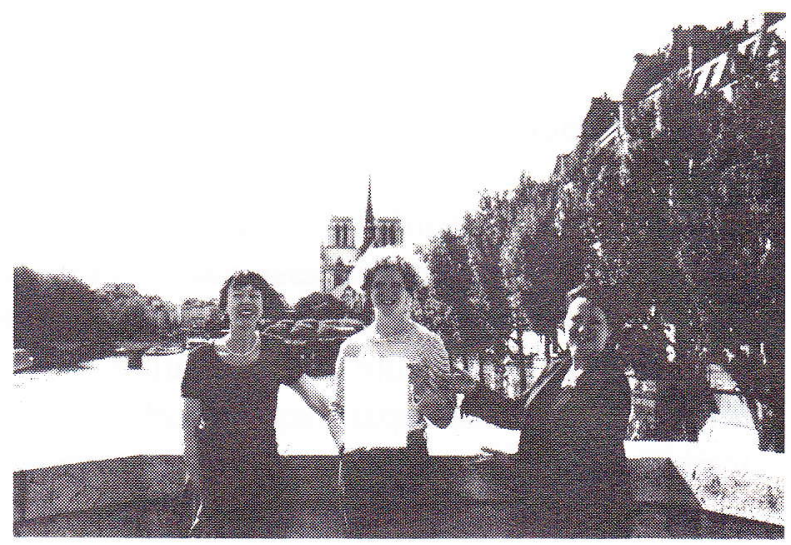

Hazel Rothera, then working at the British Council in Paris, was presented with the LIRG Postgraduate Prize in paris on May 31st 1998 by Committee members Ros Cotton (left) and Isobel Thompson (right).

Her essay Framing the subject: a subject indexing model for bibliographic databases in the humanities appeared in LIRN vol. 22 no 71. 


\section{News \& Views}

\section{contributed by Ros Cotton, October 1998}

\section{In the wake of the Comprehensive Spending Review...}

Although such a move had been rumoured, colleagues at the British Library Research and Innovation Centre were left reeling in August when they were told that they would be moving into the St Pancras building itself rather than an ignominious Portakabin, only to be told later on the same day of the Review's plans to combine RIC with the Library and Information Commission. Prestigious premises near Euston Station are now being renovated and a corporate rate being negotiated at a chic health and fitness club over the road! So the message could be, if you want your pet project funded, go seek out RIC staff when they are trapped on the Stairmaster...

[Editor's note: Since this was written we hear that "both the BL Board and the LIC had supported the transfer" and April 1st 1999 confirmed as the operative date. Rumours of possible location at 19-21 Woburn Place are (provisionally?) announced in the latest $R I C$ Research Bulletin.]

\section{C40 million for University of Industry}

The Government, in the form of Baroness Blackstone, has announced that the UfI, to be launched in Sheffield in 2000, will be funded to the tune of $£ 40$ million. The idea is to improve UK competitiveness by raising skill levels and employability. Learning will be facilitated and accelerated through use of state-of-the-art technology in a network of learning centres. In addition to the $£ 40$ million, $£ 6.25$ million has been allocated to Learning Direct, the Government's national learning help line, which is to become the UfI's information and advice service. With all this emphasis on lifelong learning it seems that anyone not learning something will have to have a jolly good excuse...!

\section{More Calls for Proposals on the way}

Continuing its policy of funding more research through Calls for Proposals covering specific areas RIC is preparing a Call for the Information Retrieval programme, for projects to start in 1999/2000. It will focus on multimedia information retrieval and retrieval from the Internet. For more information on the programme peruse the RIC web site at http://www.bl.uk/services/ric/research/ir main.html or, for a more personal contact, speak to Martin Nail 01714127044.

RIC watchers will be aware that Calls have already taken place in the library management, cooperation, conservation/preservation and value and impact areas. More information on these can be gleaned from the web site:

www.bl.uk/services/ric/ and from the invaluable and excellent BLRIC Research Bulletin No. 21

\section{Yet another acronym to remember...}

The Anderson Report concerning the need for a national information strategy for researchers acknowledged the importance of the libraries of the Research Councils; as a result a consortium of these libraries has been formed "to act in collaboration... to obtain information service supply benefits in support of research staff across the whole Research Council sector".

RESCOLINC includes the libraries of the Biotechnology and Biological Sciences Research Council, the Council for the Central Laboratory of the Research Councils, the Economic and Social Research Council, the Engineering and Physical Sciences Research Council, Medical Research Council, Natural Environment Research Council and the Particle Physics and Astronomy Research Council.

RESCOLINC anticipates its first action in the area of site licensing of electronic journals. 


\section{UKOLN}

Sterling stuff from the UKOLN Conference as reported in that august body's Newsletter - or at least something to impress fellow guests with at cocktail parties! The programme apparently ranged over such erudite topics as distributed library architectures, the desire of users for a seamless information landscape and the need to "repurpose" information to serve different needs. Delegates were also warned that in a richly networked society the existing ordered information world will become "re-chaotised" resulting in a changing public sphere - and a few other things, I shouldn't wonder. Since the future of librarians will not be in digital libraries but rather as "facilitators in an information landscape" does this mean we now have carte blanche to call ourselves Information Landscape Artists? I hope the Library Association and IIS are taking note of this as they move towards amalgamating their professional organisations.

\section{Delay to Freedom of Information bill}

Interesting to read about what is going on in the States as the UK's proposed Freedom of Information Act goes onto the back burner. There is determination by the American Library Association and other bodies to secure the passage of the Government Publications Reform Act, the purpose of which is to enhance public access regardless of format. It would also guarantee permanent preservation of electronic publications: apparently many are lost at present as government agencies delete files from web sites without creating a lasting record.

As the UK accords this a lower priority - and the outcome of the February Green Paper on the future of the government statistical service is still awaited - the architects of this US legislation emphasise that in a democracy the public deserves access to documents produced with taxpayers' money.

\section{Social audit of public libraries}

For years policy makers and practitioners wrestled with the need to prove that libraries are indeed a Good Thing but always came up against the problem of over reliance on anecdotal evidence because of the lack of hard data. Since the financial climate since the 1980 s has demanded such data if libraries were not always going to a soft option for local authority expenditure cuts, it was timely for BLRIC to fund a social audit of public libraries.

The intention was to devise an acceptable methodology for quantifying such "soft" evidence. It is disappointing that now the report has emerged (New measures for the new library: a social audit of public libraries), it claims to demonstrate the social impact of the public library but still is forced back onto qualitative assessments and therefore does not exactly break new ground. Publicity for the report states that it "argues that qualitative data, properly gathered, are valid evidence and should be used as such by politicians and professionals". Yes, but this won't cut much ice with hard-pressed councils having to decide whether to close a library or cut the social services budget and anyway, how does one define "properly gathered?"

While this is by no means the first research project report failing to live up to its promises, it could be argued that RIC does itself no favours by publicising such findings when they add little to existing knowledge.

[Editor's Note: Reactions to this (unedited) 'red rag' are anticipated and will be welcome!] 